\title{
Clinical Trials and the Reorganization of Medical Research in post-Second World War Britain
}

\author{
HELEN VALIER and CARSTEN TIMMERMANN*
}

The rise of biomedicine is usually associated with the transformation of biological and medical research in the United States following the vast expansion of funding, both private and public, in the years after the Second World War. ${ }^{1}$ Along with the other authors in this issue, we are interested in describing this phenomenon in national contexts other than the United States. Our discussion of biomedicine in Britain draws upon many of the same themes as our fellow authors and the existing literature on the US - the new role of the state as scientific entrepreneur; the relationship between experimental medicine and clinical services; and the growing institutionalization of associations between laboratory and clinic-to emphasize the clinical trial as a privileged form of therapeutic evaluation in the post-war years. In particular we are keen to stress that the randomized clinical, or controlled, trial (RCT) in Britain developed within a period of increasing centralization of state policy and planning for health services and medical research.

The epistemological success of the RCT in demonstrating the value of the antituberculosis drug streptomycin elevated the technique to international prominence in the late 1940s. The 1948 trials of streptomycin conducted by the British Medical Research Council (MRC), along with similar trials in the United States, are usually recognized as the world's first randomized controlled trials. Indeed, the streptomycin trials, and the trials of PAS and isoniazid that followed in the early 1950s, did combine the statistical technique of randomization, with new organizational techniques, such as the division of specialist labour, and central review and data collection, across multiple sites of study. As Peter Keating and Alberto Cambrosio, Ilana Löwy, and Harry Marks have shown for the US, the success of the co-operative (that is, multi-centre) clinical trial was intimately related to the new role of the federal government, through

(C) Helen Valier and Carsten Timmermann 2008

*Helen Valier, PhD, The Honors College at the University of Houston, 212 M.D. Anderson Library, Houston, TX 77204-2001, USA; hkvalier@uh.edu Carsten Timmermann, $\mathrm{PhD}$, Centre for the History of Science, Technology \& Medicine, University of Manchester, Simon Building, Brunswick Street, Manchester M13 9PL, UK; carsten.timmermann@ manchester.ac.uk

\footnotetext{
${ }^{1}$ Some important studies on the post-Second World War "biomedicalization" of health and illness in the United States include: Adele E Clarke, Janet K Shim, Lauro Mamo, Jennifer R Fosket, and Jennifer R
}

Fishman, 'Biomedicalization: technoscientific transformations of health, illness, and US biomedicine', Am. Sociol. Rev., 2003, 68: 161-94; Jean-Paul Gaudillière, Inventer la biomédecine: la France, l'Amérique et la production des savoirs du vivant (1945-1965), Paris, La Découverte, 2002; and Peter Keating and Alberto Cambrosio, Biomedical platforms: realigning the normal and the pathological in late-twentieth-century medicine, Cambridge, MA, MIT Press, 2003. In this paper we are not dealing with the more recent, Foucaultian meanings associated with the term biomedicine: see Nikolas Rose, The politics of life itself: biomedicine, power, and subjectivity in the twenty-first century, Princeton University Press, 2007. 


\section{Helen Valier and Carsten Timmermann}

the National Institutes of Health, in funding such organized biomedical research. ${ }^{2}$ Similarly, using treatment trials for tuberculosis and lung cancer as our case studies, we show for Britain that the promotion and organization of co-operative trials was fundamentally part of the MRC's new role within the state. We argue that the Council pursued the trials as a means of unifying a research landscape that was characterized by localism and suspicions about MRC plans to remodel clinical research to resemble the basic sciences.

We argue further that a controlled trial must be understood both as a tool to produce knowledge persuasive enough to direct best clinical practice, and as a powerful means to discipline research workers in disparate settings. ${ }^{3}$ Neither process was particularly straightforward. It took years of clinical trials of anti-tuberculosis chemotherapies before sanatorium treatment and bed-rest were entirely given up by British physicians. The MRC's 1955 trials carried out in the Indian city of Madras (Chennai) are generally regarded as conclusively showing domiciliary care to be redundant in the presence of chemotherapeutic intervention; however, we argue that trials influenced but did not change practice overnight. Similarly, the lung cancer trials initiated by the MRC following a conference in 1957 as part of a broader programme of therapy trials for various types of cancer, proved difficult to run. Furthermore, they did not resolve the controversy as intended, not least because procedures and treatment pathways were well established before the trials. Serious historical attention to the organizational details, reception of such RCTs, and resulting changes in practice, is needed if we are not to be blinded by hindsight. Before we turn to the trials, however, we need to discuss the role of the $\mathrm{MRC}$ in the history of biomedicine in Britain and the place of the Council within the post-war socialized National Health Service (NHS).

\section{The MRC and Biomedical Research in Britain}

As Keating and Cambrosio have noted, the term "biomedicine", according to the Oxford English Dictionary, first appeared in the twelfth edition of the American publication, Dorland's Medical Dictionary, published in 1923. ${ }^{4}$ Biomedicine, according to this definition, was "clinical medicine based on the principles of physiology and biochemistry". This resonated strongly with the priorities for medical research as outlined by the contemporary leadership of the British MRC, created as the Medical Research Committee under the 1911 National Insurance Act. ${ }^{5}$ During the Great War,

\footnotetext{
${ }^{2}$ Peter Keating and Alberto Cambrosio, 'From screening to clinical research: the cure of leukemia and the early development of the cooperative oncology groups, 1955-1966', Bull. Hist. Med., 2002, 76: 299-334; Ilana Löwy, Between bench and bedside: science, healing, and interleukin-2 in a cancer ward, Cambridge, MA, Harvard University Press, 1996, ch. 1; Harry M Marks, The progress of experiment: science and therapeutic reform in the United States, 1900-1990, New York, Cambridge University Press, 1997.

${ }^{3}$ On the meanings of the term "control" in this context, see Martin Edwards, Control and the
}

\author{
therapeutic trial: rhetoric and experimentation in \\ Britain, 1918-48, Amsterdam and New York, \\ Rodopi, 2007. \\ ${ }^{4}$ Keating and Cambrosio, op. cit., note 1 above, \\ p. 52. The authors note that the use of this term until \\ the post-war period was sporadic and not common in \\ the medical literature. \\ ${ }^{5}$ For an overview of the Medical Research \\ Council's first forty years, see Joan Austoker and \\ Linda Bryder (eds), Historical perspectives on the \\ role of the MRC: essays in the history of the Medical \\ Research Council of the United Kingdom and its
}




\section{Clinical Trials and Medical Research in Britain}

Britain's Liberal prime minister, Lloyd George, promised a new government ministry dedicated to promoting a healthier British public, and indeed a Ministry of Health was founded in 1919. With the support of Christopher Addison, a former professor of anatomy and the head of the newly founded ministry, the Medical Research Committee was reformulated in 1919 to become the Medical Research Council, commanding a substantially increased budget. Walter Fletcher, a Cambridge-trained physiologist and first Secretary of the MRC, had skilfully exploited opportunities to become more closely involved in state affairs during and after the war, and through doing so successfully transformed the nascent organization from a narrowly focused, tightly controlled, disease specific research committee to a broadly defined, ambitious research organization with a great deal of autonomy in its own affairs. ${ }^{6}$ Under Fletcher's direction the Council's attention broadened to encompass a wide range of diseases and medical conditions, and the seemingly (to Fletcher) more promising pastures of basic, "pure" biomedical research. ${ }^{7}$ Such a shift was enshrined in the concordat drawn up in 1924 directing the Ministry of Health to concern itself with epidemiological field research (mostly public health and community matters) and "applied research" on clinical problems, while the MRC was to initiate and organize all new research in the basic and biomedical sciences. ${ }^{8}$ Clinicians were not well represented on the Medical Research Council during the 1920s and 1930s; Fletcher famously believed that bench scientists - be they bacteriologists, virologists, immunologists, biochemists, pathologists or physiologists-were the most appropriate guardians of basic medical and clinical research; an assumption vigorously challenged by his opponents. ${ }^{9}$

The basic medical sciences were certainly rising in prestige in the 1920s. The development of salvarsan to treat syphilis; new analgesics for surgery; "biologicals" (like hormones and vitamins), including treatments for deficiency diseases such as diabetes (insulin) and pernicious anaemia (extracts of liver) - all demonstrated how apparently intractable clinical problems could be manipulated and at least partially solved within the laboratory. This new pharmacopoeia encouraged a new relationship between the state, pharmaceutical companies, and clinics intent on developing patient trials. ${ }^{10}$ Multi-centre, controlled, trials thus began to emerge onto the international clinical research scene during the 1920s and 1930s. While the MRC funded a statistical research unit under Major Greenwood, a disciple of Karl Pearson and friend of Fletcher, the use of

predecessor, the Medical Research Committee, 1913-53, Oxford University Press, 1989.

${ }^{6}$ Joan Austoker, 'Walter Morley Fletcher and the origins of a basic biomedical research policy', in Austoker and Bryder (eds), op. cit., note 5 above, pp. 23-33.

${ }^{7}$ Joan Austoker and Linda Bryder, 'Preface', in Austoker and Bryder (eds), op. cit., note 5 above, pp. v-vii.

8 'Relations between the Ministry of Health and the Medical Research Council, 12 February, 1924', UK National Archives (hereafter NA), MH 123/498. The 1924 concordat was reaffirmed by both parties in 1949 in response to the implementation of the National Health Service Act.

\footnotetext{
${ }^{9}$ Austoker, op. cit., note 6 above. There were some notable exceptions, such as the (MRC funded) first full-time professor of medicine at UCL, Thomas Renton Elliott, a friend of Fletcher. Elliot trained as a physiologist at Cambridge before going on to medical school.

${ }^{10} \mathrm{~J}$ Liebenau, 'Industrial R \& D in pharmaceutical firms in the early twentieth century', Business History, 1984, 26: 329-34; John P Swann, Academic scientists and the pharmaceutical industry, Baltimore, Johns Hopkins University Press, 1988; M Weatherall, In search of a cure: a history of pharmaceutical discovery, Oxford University Press, 1990.
} 


\section{Helen Valier and Carsten Timmermann}

statistical methods for experimental design and data analysis remained somewhat limited. ${ }^{11}$ Sophisticated methods of statistical experimental design and data analysis were developed in the inter-war period, but were not generally implemented until after the Second World War. The work of the British biologist and statistician R A Fisher on randomization and variance analysis, for instance, published as Statistical methods for research workers (1925) and The design of experiments (1935), was only slowly accepted but, nevertheless, influenced a generation of post-Second World War biomedical researchers. One reason for this shift, in Britain at least, was that the new system of state medicine introduced in 1948 created conditions favouring proposals to make medicine more rational and efficient.

During the early twentieth century, the MRC had provided a new institutional home for the basic and paramedical sciences of physiology, biochemistry and pharmacology in the National Institute for Medical Research, founded in 1914. The Council was, however, much less successful in implementing academic clinical research in the so-called "professorial" units (first in London and later in the provinces), staffed by full-time clinicians with strong research backgrounds. Indeed, the efforts of Fletcher and his successor Edward Mellanby to establish British academic clinical research on a firm footing experienced mixed fortunes in inter-war Britain. ${ }^{12}$ Thus despite MRC attempts to establish a new independent biomedical research institute and to fund professorial units, British clinical research continued in large part to be funded through local, piecemeal efforts. Those wishing to conduct medical research applied for grants from a wide range of charities, hospital endowment funds, universities and the MRC. They then negotiated access to clinical facilities through individual hospital authorities. The legacy of such arrangements posed a considerable logistical problem for any scheme seeking to centralize and standardize health policy. After the Second World War, changes to hospital funding brought about by the implementation of the National Health Service (NHS) Act in 1948 had profound effects on this culture of localism in clinical research. ${ }^{13}$

\footnotetext{
${ }^{11}$ For problems facing early co-operative trial groups, see Harry M Marks, 'Notes from the underground: the social organization of therapeutic research', in Russell C Maulitz and Diana E Long (eds), Grand rounds: one hundred years of internal medicine, Philadelphia, University of Pennsylvania Press, 1988, pp. 297-336; and on the influence of Pearson and Greenwood, Eileen Magnello, 'The introduction of mathematical statistics into medical research: the roles of Karl Pearson, Major Greenwood and Austin Bradford Hill', in Eileen Magnello and Anne Hardy (eds), The road to medical statistics, Amsterdam and New York, Rodopi, 2002, pp. 94-124.

${ }^{12}$ Apart from the conspicuous successes of the Rockefeller-funded University College Hospital (London) unit established under Thomas Lewis, the inter-war professorial unit system generally proved to be an inadequate basis on which to produce a strong British tradition in academic clinical research. Over the years, despite much discussion and attempts to ignite wider interest in the unit system, the units
}

\begin{abstract}
themselves remained mostly clustered in London teaching hospitals, becoming progressively more over-burdened with teaching duties. See Christopher C Booth, 'Clinical research since 1945', in Ghislaine Lawrence (ed.), Technologies of modern medicine, London, Science Museum, 1993, pp. 148-50; and Christopher C Booth, 'Clinical research', in W F Bynum and Roy Porter (eds), Companion encyclopedia to the history of medicine, London and New York, Routledge, 1993, pp. 205-29; D Fisher, 'The Rockefeller Foundation and the development of scientific medicine in Great Britain', Minerva, 1978, 16: 20-41; H K Valier, 'The politics of scientific medicine in Manchester, c.1900-1960', PhD thesis, University of Manchester, 2002.

${ }^{13}$ For an overview of the origins and development of the NHS, see Charles Webster, The National Health Service: a political history, Oxford University Press, 1998; Rudolph Klein, The new politics of the NHS, 3rd ed., London, Longman, 1995; Geoffrey Rivett, From cradle to grave: fifty years of the NHS, London, King's Fund, 1998.
\end{abstract}




\section{Clinical Trials and Medical Research in Britain}

Throughout the inter-war period, the Ministry had increasing relied on the advice of the MRC about how best to conduct and appropriately direct its own efforts, while leaving the Council largely to its own devices. ${ }^{14}$ During the late 1930s, the Ministry devised a plan for a nationwide organization of Emergency Medical Services, to be put into operation in the event that Britain would go to war. ${ }^{15}$ In drawing up the plans, the government sought advice from the MRC on topics of national defence, notably on how best to protect the public in the aftermath of an attack with biological weapons. ${ }^{16}$ At the outbreak of the Second World War, the Ministry inaugurated the Emergency Public Health Laboratory Service, a network linking (mostly university) clinical laboratories nationwide, for which numerous MRC subcommittees were given executive operational responsibilities. ${ }^{17}$ Thus in 1948, when the activities and resources of the nation's hospitals passed to the control of the Ministry of Health, ${ }^{18}$ there seemed little doubt that the MRC would play a significant role in the national organization of research.

The final wording of the National Health Service Act had been settled only after often bitter negotiations between government planners, especially Aneurin Bevan, the chief architect of the NHS, and the medical professional bodies, notably the Royal Colleges. Interference with professional traditions and autonomy had been at the heart of many of these disputes, and the prospect of the Ministry (or the MRC) delving into the research activities of individual hospitals was controversial. Arthur Landsborough Thomson, a leading member of the MRC executive, made it clear in private correspondence that the Council had no wish to meddle with "low-level" research "consisting mainly in the observation of cases and the trial of methods, that they [clinicians] can take in their stride while treating patients". ${ }^{19} \mathrm{He}$ did, however, indicate that the Council expected to extend its domain to the overall direction of British medical research, and to do so without pandering to the whims of individual institutions and clinicians, no matter how powerful and well endowed. ${ }^{20}$

The creation of more than fifty new full-time chairs in clinical subjects between 1947 and 1952 substantially increased Britain's clinical research infrastructure. ${ }^{21}$ One reason for this change was the reorganization of the universities. The new University Grants Committee (UGC), funded directly from the Treasury, induced essentially private, autonomous institutions to become part of a national university system. The NHS brought this system into a closer relationship with teaching hospitals and medical schools. The Interdepartmental Committee on Medical Schools (Goodenough Committee) set up by the

\footnotetext{
${ }^{14}$ See comments in 'Medical research at hospitals in the National Health Service: Transfer of major schemes to Medical Research Council, 1949-1953', NA, MH 123/498.

${ }^{15}$ On the founding of the Emergency Medical Service, see C L Dunn, The emergency medical services, London, HMSO, 1952-1953, vol. 1 .

${ }^{16}$ A Landsborough Thomson, Half a century of medical research. Volume 2: The programme of the Medical Research Council (UK), London, HMSO, 1975, p. 255.
}

\footnotetext{
${ }^{17}$ Linda Bryder, 'Public health research and the MRC', in Austoker and Bryder (eds), op. cit., note 5 above, pp. 59-81.

${ }^{18}$ At least those of England, Wales and Northern Ireland did-Scottish hospitals came under the jurisdiction of the Scottish Secretary of State for Health, a separate body but accountable to the British Ministry of Health.

${ }^{19}$ A Landsborough Thomson to J E Pater, 27 May 1949, NA, MH 123/498.

${ }^{20}$ Ibid.

${ }^{21}$ Francis R Fraser, 'The challenge to the medical profession', Br. med. J., 1960, ii: 1822-6.
} 


\section{Helen Valier and Carsten Timmermann}

government in 1942 to advise on post-war reconstruction, had come out strongly in favour of a regional organization of teaching, service and research. ${ }^{22}$ This model of regionalization, structured around the major teaching hospitals and their affiliated universities, was at the heart of Bevan's NHS. Thus the new NHS ushered in new institutional opportunities for the pursuit of clinical academic medicine in Britain, and the MRC, keen to capitalize on these changed circumstances, promoted a quite specific vision of how that pursuit be best conducted.

In 1953 a Ministry of Health report, Clinical research in relation to the National Health Service, announced the establishment of a Clinical Research Board (CRB), and outlined the need for the new body:

clinical research ... needs to be organised on a United Kingdom basis. Such may range from problems of basic clinical research to broad investigations of the applicability of a remedy or the prevalence of an illness. We suggest that the central organisation could best promote clinical research of this nature by adopting, on the model of the Medical Research Council's practice, the policy of giving research grants and setting up clinical research units. ${ }^{23}$

According to the report, the $\mathrm{CRB}$, or one of its sub-committees, would in future assess large research grants and distribute resources according to "research priorities" and the existence, or not, of similar projects. "Decentralized" research funded locally by hospitals and local authorities was still allowed under this new regime, but these plans too had to be submitted for approval by the Ministry of Health, in consultation with the $\mathrm{CRB} .{ }^{24}$ In any case, the increasingly tight financial environment strongly affected the culture of research, according to a 1956 government Treasury minute:

... the tightness of the hospitals' allocations for hospital running costs and the shortage of funds for development would ensure that money was not frivolously spent on research; there was no danger of a re-expansion in areas where work would have been taken away by C.R.B. The removal of the top research workers would of itself bring about a contraction. ${ }^{25}$

In other words, the scarcity of resources within the NHS system in the 1950s created the financial means to discipline hospital authorities into certain types of co-operation with central authorities. Hospitals had fewer and fewer resources to devote to research; by the mid-1950s the NHS was in the midst of a funding crisis affecting all its functions. ${ }^{26}$ Lack of money generated opportunities for greater intervention. For instance, in a 1955 memo to the Chief Medical Officer, Sir John Charles, Harold Himsworth, MRC Secretary from 1949 to 1968, was explicit about the mechanism for bringing academic units into line and up to standard, "What one envisages happening ... is that the loose control now existing over salaried workers will be replaced by tight control based on short-term grants." 27

\footnotetext{
${ }^{22}$ Ministry of Health and Department of Health for Scotland, Report of the inter-departmental committee on medical schools, London, HMSO, 1944.

${ }^{23}$ Clinical research in relation to the National Health Service, London, HMSO, 1953, p. 7.
}

\footnotetext{
${ }^{24} \mathrm{NA}, \mathrm{MH}$ 123/499 contains examples of such returns.

${ }^{25}$ Meeting between the MRC, Treasury and Ministry, 'Transfer of Clinical Research', 10 Oct. 1956, NA, FD 7/241.

${ }^{26}$ Rivett, op. cit., note 13 above, ch. 2.

${ }^{27} 26$ Nov. 1955, NA, MH 123/498.
} 


\section{Clinical Trials and Medical Research in Britain}

Thus the CRB, modelled on, organized by, and responsible to, the MRC offered an unprecedented opportunity to realize Fletcher's original dream of shaping the overall direction of British biomedical research. In the next section we will look at clinical trials to illustrate how the Council aimed, not always successfully, to change both research and clinical practice along the lines of what its members viewed as good science.

\section{Clinical Trials}

Clinical researchers conceived of controlled trials long before they acquired the financial, institutional and organizational means to carry them out. ${ }^{28}$ In Britain, the development and marketing of insulin in the 1920s led to the creation in 1931 of an MRC Therapeutic Trials Committee, designed, in co-ordination with the Association of British Chemical Manufacturers, to speed up the process of making potentially useful synthetic products into usable clinical products. Organizing large-scale co-operative trials and gleaning good data proved extremely difficult in practice. ${ }^{29}$ As discussed above, the MRC's endeavours to foster academic clinical research were severely constrained, from its inception, by the lack of an effective inter-war university base in experimental medicine. ${ }^{30}$ Wartime exigencies changed this. In Britain as elsewhere, the Second World War stimulated programmes of targeted academic research into everything from weapons systems to public health. ${ }^{31}$ The financial, institutional and organizational means were at last being found for large-scale co-operative research in Britain.

In 1946 a team of British physicians, statisticians, bacteriologists, and radiologists came together to form the Tuberculosis Chemotherapy Trials Committee of the MRC. They began to organize what would be the world's first randomized controlled clinical trial. ${ }^{32}$ Three major MRC centres were involved in the committee: the Tuberculosis

\footnotetext{
${ }^{28}$ Marks, op. cit., note 11 above; Edwards, op. cit., note 3 above.

${ }^{29}$ The trials of "liver-extract" for pernicious anaemia in the 1920 s and 1930 s, and patulin for the common cold in the early 1940s were early attempts by the MRC to co-ordinate rigorous trials. The "liver extract" trials collapsed partly due to suspicions on the part of senior Council figures that certain clinical researchers were using the scheme for personal benefit (Valier, op. cit., note 12 above, ch. 3). The patulin trials, on the other hand, were significantly more successful in terms of organization, but they did not show the drug to be efficacious. Iain Chalmers and Mike Clarke have argued that it was this lack of efficacy that caused the trial to be virtually ignored as the immediate model for the subsequent, much celebrated, trials of streptomycin for tuberculosis. See Iain Chalmers and Mike Clarke, 'The 1944 patulin trial: the first properly conducted multicentre trial conducted under the aegis of the British Medical Research Council', Inter. J. Epidemiol., 2004, 33: 253-60.

${ }^{30}$ Christopher C Booth, 'Clinical research', in Austoker and Bryder (eds), op. cit., note 5 above, pp. 205-41, p. 205. By the 1930s the academic clinical
}

research base sponsored by the MRC included university hospitals and clinics in London, Sheffield, Edinburgh and St Andrews, and the Surgical Unit at The Welsh National School of Medicine, Cardiff, but elsewhere MRC money was scarce.

${ }^{31}$ On the increase in funding of military-related scientific research in Britain during the Second World War, see, for example, Brian Balmer, Britain and biological warfare: expert advice and science policy, 1930-1965, Basingstoke, Palgrave, 2001; David Edgerton, Warfare state: Britain, 1920-1970, Cambridge University Press, 2006; and Bryder, op. cit., note 17 above.

${ }^{32}$ Medical Research Council, 'Streptomycin treatment of pulmonary tuberculosis', $\mathrm{Br}$. med. J., 1948, 2: 769-82. For discussion of the MRC's early trial, see Lise Wilkinson, 'Sir Austin Bradford Hill: medical statistics and the quantitative approach to disease', Addiction, 1997, 92: 657-66; and A Yoshioka, 'Use of randomisation in the Medical Research Council's clinical trial of streptomycin in pulmonary tuberculosis in the 1940s', Br. med. J., 1998, 317: 1220-3. Yoshioka questions the extent to which the trial should be considered as truly novel in this regard, and considers the wider social and 


\section{Helen Valier and Carsten Timmermann}

Research Unit at the MRC laboratories in Hampstead; the Institute for Diseases of the Chest at the Brompton Hospital, London; and the Statistical Unit at the London School of Hygiene and Tropical Medicine. The directors of these three centres, Philip D'Arcy Hart, J G Scadding, and Austin Bradford Hill, respectively, directed the design of the trial protocol, and oversaw the central collection and analysis of results from 100 physicians across the UK. The trial compared a group of pulmonary tuberculosis patients treated with bed-rest with a group prescribed bed-rest combined with the new American antibiotic, streptomycin. When published in 1948, the results showed conclusively that the drug did have therapeutic benefits over bed-rest alone; the trial was praised around the world for the elegance of its planning and design, as well as for the far-reaching usefulness of its findings. ${ }^{33}$ There were, however, certain unusual features of the trial design that suited the particular case and led to its successful organization and execution, but which were not easily reproducible in other contexts. Briefly, these were: a very specific group of patients, and a relatively sophisticated monitoring technology.

The original trials committee worked with a carefully selected group of willing physicians, all sharing considerable experience in the assessment and treatment of tuberculous patients, and all eager to try out this new American therapy within the rigours of the newly defined "clinical trial". The choice to treat only a very specific type of tuberculosis patient-one defined as "acute progressive bilateral pulmonary tuberculosis of presumably recent origin, bacteriologically proved, unsuitable for collapse therapy, age group 15-25"34 (that is, unsuitable for forms of therapy other than bed-rest) - meant that random allocation to a "control" group (bed-rest only) was relatively unproblematic. The fact that tuberculosis was commonly monitored radiographically gave the Committee and its researchers a means of central assessment, since all X-ray films were submitted to the trials Committee along with case reports. All this meant that the Committee's report in 1948, despite being based on only 100 patients, was confident in its endorsement of streptomycin therapy as a great improvement on existing treatments, albeit only for one specific, not very common, kind of tuberculosis. The report urged immediate further research to determine the possible wider applicability of streptomycin, and to investigate optimal dosage, ideal duration of treatment, and how to deal with drug-resistant bacilli. ${ }^{35}$

Fears over toxic effects and bacterial resistance soon brought controversy over streptomycin, stimulating the trialling and introduction of PAS and isoniazid in the early $1950 \mathrm{~s} .{ }^{36}$ As these drugs were shown to be highly effective, subsequent trials did not include, on ethical grounds, an "untreated" (bed-rest alone) group. Rather, clinical trials for anti-tuberculosis therapy became complex networks comparing multiple

political context of centrally controlled randomization. On the wider significance of tuberculosis in post-Second World War Britain, see Anne Hardy, 'Reframing disease: changing perceptions of tuberculosis in England and Wales, 1938-70', Hist. Res., 2003, 76 (194): 535-56.

${ }^{33}$ As described in the summary reports of current literature for the period carried by the British Medical Annual: A Yearbook of Treatment and Practitioner's Index.

\footnotetext{
${ }^{34}$ Medical Research Council, op. cit., note 32 above, p. 770 .

${ }^{35}$ Ibid., pp. $780-1$

${ }^{36}$ Ibid., pp. 769-70. Despite the various toxicity scares surrounding streptomycin, and the hype and "anti-hype" accompanying its testing phase (for details see Yoshioka, op. cit., note 32 above), the trial, none the less, recruited well and progressed smoothly.
} 


\section{Clinical Trials and Medical Research in Britain}

treatments-chemical, surgical, physical-in different combinations, often linked back to the results of the "untreated" (i.e., bed-rest) cohort of the original trial. ${ }^{37}$ An opportunity for a simpler, potentially more conclusive, study came about in the mid-1950s, when a major testing facility was established in the Indian city of Madras. This study was an international endeavour, combining the efforts of the British Medical Research Council, the World Health Organization, the government of Tamil Nadu and the Indian Council for Medical Research. ${ }^{38}$ The Madras trials sought to establish whether the use of chemotherapies could wholly remove the need for sanatorium care for tuberculosis, which developing countries could ill-afford. The Madras trials showed that tuberculous patients could be safely treated at home and with chemotherapy alone, and these results had profound effects on both Indian and WHO policy. Back in Britain the trial did not, however, eliminate prescriptions of bed-rest, followed by very long closely supervised courses of therapy. ${ }^{39}$ Although sanatorium care for the treatment of tuberculosis in the richer nations fell with the declining domestic incidence of the disease, the new treatments did not sweep away older forms of care. While chemotherapy became common during the early to mid-1950s, surgery, sanatorium and bed-rest all remained prominent features of the British approach to tuberculosis treatment. ${ }^{40}$ The principles that underpinned sanatorium care-fresh-air, rest and good nutrition-remained firmly implanted in the clinical mind when dealing with tuberculous patients. Doctors in Britain were reluctant to launch treatment trials using chemotherapy alone, especially for those cases in which the disease was much advanced. When the Tuberculosis Society of Scotland launched a major study in the late 1950s to investigate whether bed-rest added value to chemotherapy treatment, or whether it could be dispensed with, only "highly co-operative" patients with "mild forms" of the disease were chosen to participate. ${ }^{41}$

We are not suggesting that the 1948 trials and the 1955 Madras trials did not produce clear and convincing evidence-far from it. Rather, we suggest that the influence of trial results on existing clinical practice was neither straightforward nor uncontested, even in the presence of supposedly overwhelming evidence. It is clear that the streptomycin trials led to a widespread uptake of the RCT as an effective means to determine and compare therapeutic efficacy, but protocol design was an increasingly complex and contentious matter, as was the translation of trial findings into practice. The special circumstances

\footnotetext{
${ }^{37}$ This notion of "linking" trials is discussed by J G Scadding, 'Clinical aspects of controlled trials in pulmonary tuberculosis', in Controlled clinical trials, Oxford, Blackwell, 1960, pp. 52-6.

${ }^{38}$ Sunil Amrith, "In search of a "magic bullet" for tuberculosis: South India and beyond, 1955-1965', Soc. Hist. Med., 2004, 17: 113-30; H Valier, 'At home in the colonies: the WHO-MRC trials at the Madras Chemotherapy Centre in the 1950s and 1960s', in M Worboys and F Condrau (eds), Tuberculosis then and now: interdisciplinary perspectives on a post-modern plague, Montreal, McGill-Queens University Press, forthcoming.

${ }^{39}$ A 1961 report by the British Tuberculosis Association recommended long term supervision, possibly life-long supervision, of all patients treated
}

with chemotherapy for their tuberculosis. See 'Relapse in pulmonary tuberculosis: an analysis of the fate of patients notified in 1947, 1951 and 1954. Report from the Association's Research Committee', Tubercle, 1961, 42, 178-86.

${ }^{40}$ James L Livingstone, 'Observations on the treatment of pulmonary tuberculosis at the present time', Br. med. J., 1955, i: 243-50.

${ }^{41} \mathrm{D} \mathrm{T}$ Kay, 'The treatment of pulmonary tuberculosis at work: a controlled trial. An interim report by the Research Committee of the Tuberculosis Society of Scotland', Tubercle, 1957, 38: 375-81; Report from the Research Committee of the Tuberculosis Society of Scotland, 'The treatment of pulmonary tuberculosis at work: a controlled trial', Tubercle, 1960, 41: 161-70. 


\section{Helen Valier and Carsten Timmermann}

of the 1948 and 1955 trials were not commonly found in clinical practice, so the fact that the RCT went from strength to strength on the clinical research scene from the 1950s onwards, suggests a strong relationship between this form of knowledge formation and organization and the emerging institutional infrastructure of clinical research. We therefore propose that epistemological success alone did not create RCTs as the axis of clinical research in the late 1950s, but rather that the technique was co-produced within the new political and organizational infrastructure of post-war British medicine, which itself was expected to benefit from the existence of the controlled trial. ${ }^{42}$

The case study on the MRC lung cancer therapy trials shows this more clearly. If the MRC could bring cancer research-with its diverse sources of funding, multiple sites of excellence, high public and political profile, and variously industrial, academic, clinical, and charity research agenda and modus operandi-under its own control, then it would have established a precedent for MRC co-ordination across the whole range of biomedical research spaces in the UK. The territory of cancer research was far from empty, and any MRC claims on it were stridently contested during the first part of the twentieth century. Cancer research offered the kind of close connections between the bench-side and bedside to which Fletcher and his colleagues aspired, but their approach was not welcomed by some senior practising clinicians, who had a more sceptical outlook on the claims of bioscience. ${ }^{43}$ In cancer research such conflict and reshaping was especially visible where, aside from local (hospital endowment funds) and MRC efforts, two large and well-funded clinician-led charities operated: the Imperial Cancer Research Fund (ICRF, founded in 1902) and the British Empire Cancer Campaign (BECC, founded in 1923). ${ }^{44}$ Clinicians and scientists interested in cancer already had the resources of these charities and of cancer centres such as the Marsden and Christie hospitals in London and Manchester to draw upon. Across the nation's hospitals, local interests and practices had grown up around cancer, and these too proved difficult for the MRC to manage until after the introduction of the NHS in 1948.

Cancer therapy trials, like the ongoing tuberculosis trials, were emblematic of the problems emerging within co-operative trial groups during the late 1950s. Researchers increasingly faced the prospect of testing therapies for complicated, chronic ailments for which there already existed multiple treatments, and for which the effects of new therapeutics were often highly contested. Unlike tuberculosis, however, with its successes in combination chemotherapy and the short-course chemotherapy regimes developed in the $1970 \mathrm{~s},{ }^{45}$ cancer trials often delivered at best marginal benefits, with

\footnotetext{
${ }^{42}$ Here we are using "co-produced" in the sense outlined by Sheila Jasanoff in the introductory essay to Sheila Jasanoff (ed.), States of knowledge: the coproduction of science and social order, London, Routledge, 2004, especially p. 6.

${ }^{43}$ Joan Austoker, A history of the Imperial Cancer Research Fund, 1902-1986, Oxford University Press, 1988, pp. 73-6.

${ }_{44}$ Austoker provides an excellent summary of these complex and shifting relationships, ibid., pp. 139-204. She argues that even in the early years of Fletcher's secretaryship, he had been determined to see all medical research in the UK come under the
}

jurisdiction of the MRC. He therefore objected both to the (clinician-led) British Empire Cancer Campaign's refusal to co-operate in the administration of funds for cancer research, and the Ministry of Health's own planned programme of research. Arguments over the Ministry's cancer research initiative were a significant aspect of the drawing up of the 1924 concordat, in order that Fletcher and the Chief Medical Officer of Health, George Newman, might clarify their specific, respective fields of influence.

${ }^{45}$ See D A Christie and E M Tansey (eds), Shortcourse chemotherapy for tuberculosis, London, 


\section{Clinical Trials and Medical Research in Britain}

endpoints more controversial and success more difficult to assess. As such, they make an excellent counter-example to the tuberculosis case. As we will demonstrate, the complex and contested data derived from these ever more complex and formal trials, along with rows over design and execution, became ever more common. Nevertheless, such controversy did not undermine the progress of the clinical trial as an increasingly essential feature of clinical-biomedical research. Why this should have been the case is, we argue, as much a question of the politics as of the content of British clinical research. The co-operative clinical trial both constructed and maintained new forms of organization and relationships in academic medicine.

On 31 January 1957, the MRC held a conference on the evaluation of different methods of cancer therapy. The organization of the conference was itself very much a product of the age. Following the publication of a report by the MRC's Committee on the Clinical Applications of Nuclear Physics on supervoltage radiotherapy, the CRB had recommended that this new technology, along with other cancer therapies, should be investigated in large clinical populations under the auspices of the MRC. ${ }^{46}$ The chairman of the Committee on the Clinical Applications of Nuclear Physics, Brian Windeyer, also chaired the conference. Windeyer, professor of radiotherapy at the Middlesex Hospital Medical School, belonged to a generation of medical academics that actively shaped the post-war reorganization of both cancer services and medical research. He recommended to the conference that the MRC "should consider undertaking an investigation into the treatment of certain tumours which appeared particularly suitable for short-term study". ${ }^{47}$ The resulting agenda set by the recommendations of the 1957 conference was heavily geared towards the evaluation of the new radiotherapy machines. ${ }^{48}$ Following the preliminary findings reported by the Committee on the Clinical Applications of Nuclear Physics, the conference participants expected positive and convincing results. ${ }^{49}$ Radiotherapy appeared to be the form of treatment from which these British cancer specialists expected most innovative impulses. ${ }^{50}$ This was perhaps not surprising, given the strength of the field in Britain, the role that the MRC had played in the distribution of radium in the inter-war period, and the strong presence of prominent radiotherapists at the conference. ${ }^{51}$ Cancer chemotherapy, by contrast, was in its infancy, and beyond the networks surrounding the Chester Beatty Institute in London

Wellcome Trust Centre for the History of Medicine at UCL, 2005.

46 'The value of supervoltage therapy in the one to ten $\mathrm{MeV}$ range', NA, FD 7/698; 'Informal Conference on the Evaluation of Different Methods of Cancer Therapy', invitation, ibid.

47 'Evaluation of different methods of cancer therapy: recommendations of the Council's steering committee', NA, FD 7/327. The other participants, besides Windeyer were: P Armitage, D Baird, J Bruce, S Cade, Lord Cohen, D A G Galton (representing A Haddow), G Hadfield, A Bradford Hill, G Jefferson, R McWhirter, P R Peacock, R Platt, R Paterson, R W Scarff and L J Witts, as well as F J C Herrald and M Gorrill from MRC Headquarters. Invited but unable to attend were C Dodds, A Haddow, J S Mitchell, F G Spear and D W Smithers.
48 'Evaluation of dfferent methods of cancer therapy: recommendations of the Council's steering committee', NA, FD 7/327.

49 'The value of supervoltage therapy in the one to ten MeV range', NA, FD 7/698.

${ }^{50} \mathrm{E}$ Toon, 'Does bigger mean better? British perspectives on American cancer treatment and research, 1948', J. Clin. Oncol., 2007, 25: 5831-34.

${ }^{51}$ For the history of radiotherapy in Britain, see C C S Murphy, 'A history of radiotherapy to 1950 : cancer and radiotherapy in Britain 1850-1950', PhD dissertation, University of Manchester, 1986. See also David Cantor, 'The MRC's support for experimental radiology during the inter-war years', in Austoker and Bryder (eds), op. cit., note 5 above, pp. 181-204. 


\section{Helen Valier and Carsten Timmermann}

and the Christie Hospital in Manchester, British cancer specialists showed little interest in it. $^{52}$

In June 1957, the Council appointed a steering committee, also chaired by Windeyer, to prepare the appropriate cancer trials. ${ }^{53}$ The steering committee then appointed five ad hoc working parties for the chosen forms of cancer-carcinoma of the bronchus, oesophagus, bladder, bone sarcoma, and medulloblastoma - to assist with the task of "drawing up a co-ordinated scheme of investigation". 54 The plans of the steering committee did not meet with anything like the enthusiasm they had hoped for. Three of the working parties were disbanded in short order: the carcinoma of the oesophagus working party (chairman: D F Campbell) immediately after its first meeting, when its members agreed that the envisaged trial of radiotherapy versus surgery should not be attempted. The carcinoma of the bladder (chairman: R B Hunter) and medulloblastoma (chairman: Dorothy Russell) working parties both terminated in 1962. The bladder cancer group did not manage to recruit enough patients fulfilling the criteria for admission for the trial they were hoping to undertake; and subsequent proposals were all deemed impracticable. The medulloblastoma group gave up when they found, after undertaking retrospective studies, that comparable cases treated with usual procedures in different centres could not be matched in order to obtain a statistically significant evaluation of the results of treatment. Only the carcinoma of the bronchus (chairman: J G Scadding) and bone sarcoma (chairman: Herbert Seddon) working parties survived into the early 1970s, by which time the MRC had fundamentally reorganized its activities in cancer research, partly due to generational change, leading to a turn towards chemotherapy. ${ }^{55}$

Keating and Cambrosio have argued that the protocol-driven approach of chemotherapy trials represented a new "style of practice", or "a distinctive configuration of institutions, scientific practices, and materials that [generated] specific ways of identifying and investigating research questions, of producing and assessing results, and of regulating these activities". 56 And it was the sixth chemotherapy-focused working party, appointed in 1955 under Leslie Witts to work on leukaemia, that fared the best of all. The working party carried out a number of trials in leukaemia and myelomatosis, and in 1968 was reconstituted as an independent, permanent Council committee. The fact that there were such differences in the fortunes of the working parties suggests that the styles of practice inherent in RCTs worked best in those fields where existing therapies were weak or non-existent. In the remainder of this paper we will focus on the lung cancer studies, carried out by the tuberculosis research unit that so successfully organized the streptomycin and Madras trials, since they illustrate more of the problems that the Council faced when using clinical trials as a means of colonizing fields of research where the MRC had historically had little influence.

\footnotetext{
52 'Alexander Haddow', Biog. Mem. Fellows R. Soc., 1977, 23: 133-91, especially pp. 153-60.

${ }^{53}$ The members of the steering committee were: B W Windeyer (chairman), J S Mitchell, R B Hunter, R E Scarff, A L d'Abreu, J Gough, A Bradford Hill and L J Witts.

54 'Evaluation of different methods of cancer therapy: recommendations of the Council's steering committee', NA, FD 7/327.
}

\footnotetext{
55 'Evaluation of different methods of Cancer Therapy Committee', NA, FD 7/340.

${ }^{56}$ Peter Keating and Alberto Cambrosio, 'Cancer clinical trials: the emergence and development of a new style of practice', Bull. Hist. Med., 2007, 81: 197-223, on p. 199.
} 


\section{Clinical Trials and Medical Research in Britain}

The composition of each working party had followed the same basic design: each included a physician, a surgeon, a pathologist, and a radiotherapist, most of whom had had previous links to the MRC. In addition, Bradford Hill, representing the Council's statistical tradition, was an omnipresent factor to all. With the proposals of the working parties in hand, the committee recommended that suitable trials should not require "too elaborate an organisation" while carrying a "reasonable promise of yielding useful information", and that random allocation, while not essential, should be attempted. ${ }^{57}$ The timing, with the results of a number of conventional trials already published or about to be published, as well as the subsequent discussions within the working parties, suggests that the use of the new randomized trial approach may have had priority over the development of new therapeutic techniques. The late 1950s was a time when MRC committees of this type did begin to seek ways to standardize activities and bring all researchers up to a level of agreed best practice. The Evaluation of Cancer Therapy Committee was thus a vehicle for emphasizing the innovative approach of the RCT not only in the evaluation of new therapeutic methods, but also in the rigorous analysis of well-established methods of practice (in this case in surgery and radiotherapy). Although such a process had an obvious appeal within a cash-strapped, socialized health-care system, changes in actual clinical practice, as in the aftermath of the Madras trials, were not easily effected.

The discussions in the working parties centred predominantly on the type of studies that were both technically and ethically feasible. ${ }^{58}$ It became clear that it was not easy to find suitable, well-contained questions that could be answered by an ethically acceptable clinical trial, within the remits set by the original 1957 conference recommendations: promising, reasonably easy to organize, using randomization, and leading to further research. ${ }^{59}$ For lung cancer, Scadding, a veteran of the MRC tuberculosis trials at home and abroad, suggested three problems that might fit with the recommendations and were worth studying: first, the efficacy of surgery as opposed to radiotherapy, "which was as yet an unsolved question"; second, the efficacy of different kinds of radiotherapy; and third, the use of chemotherapy alone or in combinations with other forms of treatment. ${ }^{60}$ However, he did not believe that there was satisfactory evidence for the beneficial effects of chemotherapy, and therefore he did not think that an evaluation of its use was a suitable subject. There were also, he argued, considerable ethical objections to a comparison of surgery and radiotherapy, as about a quarter of the patients undergoing surgery survived for five years or longer. ${ }^{61}$ The Working Party settled on the idea of a trial comparing the effects of super- and ortho-voltage irradiation. It was decided to approach D'Arcy Hart at the MRC's Tuberculosis Research Unit about

\footnotetext{
57 'Evaluation of different methods of cancer therapy: recommendations of the Council's steering committee', NA, FD 7/327.

${ }^{58}$ For a more detailed account of these discussions and the trials, see Carsten Timmermann, 'As depressing as it was predictable? Lung cancer, clinical trials, and the Medical Research Council in postwar Britain', Bull. Hist Med., 2007, 81: 312-34.
}

\footnotetext{
${ }^{59}$ Minutes of the steering committee meeting on 13 Jan.1958, NA, FD 7/327; Minutes of the meeting of the Lung Cancer Working Party on 24 June 1958, ibid.

${ }^{60}$ Ibid.

${ }^{61}$ Ibid.
} 


\section{Helen Valier and Carsten Timmermann}

co-ordinating the work in collaboration with the Statistical Unit, since these units had previous experience with controlled trials. ${ }^{62}$ D'Arcy Hart, although initially reluctant because of staff shortages in his unit, eventually agreed to assist his long-time colleagues. $^{63}$

The next difficulty the working party faced was considerably more tricky: how to persuade enough potential collaborators around the country of the value of the planned study. Letters were written to centres that the Working Party considered likely participants, and a crucial meeting was prepared with twenty-nine consultant radiotherapists. It became clear during this meeting, which took place on 21 January 1961, that the radiotherapists were not enthusiastic about the protocol. Most thought that super-voltage was "obviously" preferable to ortho-voltage therapy and they were not convinced that a trial made sense. ${ }^{64}$ Many suggested, instead, that a trial should be designed to "compare the progress and survival rate of patients with presumed undifferentiated carcinomas of the lung following surgical treatment, with that following radiotherapy". ${ }^{65}$ Faced with the prospect of a trial in which the leading radiotherapists were unwilling to participate, the organizers returned to the drawing board. Another consultation meeting was scheduled with both consultant surgeons and radiotherapists on 25 July $1961 .{ }^{66}$ Scadding introduced the agenda by stating that "there appeared to be a clinical problem as to the right advice to give a patient with a histological report of an undifferentiated carcinoma of the bronchus-whether to advise surgery or radical radiotherapy" ${ }^{67}$ Defining the problem in this way helped to overcome ethical problems, and discussion with the surgeons indicated that there was indeed disagreement among them. While some saw it as "proven" that resection, where possible, was always superior to other forms of treatment, others argued that for this type of tumour it was time to move away from surgical treatment as the results were uniformly poor, and turn to radiotherapy or chemotherapy. Finally the Working Party returned to an option for a trial design that its members had dismissed at an earlier stage of the discussion, but now with a specific focus on anaplastic or undifferentiated carcinoma of the lung. ${ }^{68}$ Restricting eligibility on grounds of the histological characteristics of the tumour had made feasible a study that originally was unacceptable on ethical grounds.

The results of the trial were disappointing. After two years, only three of the original seventy-one surgical patients and ten of the seventy-three radiotherapy patients were still alive. According to the report in the Lancet,

The number of survivors at 24 months is so small that further statistically significant differences between the series in this respect cannot now arise. Despite the slightly higher proportion of short-term and long-term survivors in the radical radiotherapy series both policies have produced

\footnotetext{
${ }^{62}$ Memorandum, 8 Oct. 1959, NA, FD $7 / 327$.

${ }^{63}$ D'Arcy Hart to Gorrill, 15 March 1960, NA, FD 23/1163.

${ }^{64}$ Ibid. and Draft Memorandum, n.d., NA, FD $7 / 327$.

${ }^{65}$ Ibid.
}

\footnotetext{
${ }^{66}$ Minutes of a Special Meeting with Consultant Surgeons and Radiotherapists, 25 July 1961, NA, FD $7 / 327$

${ }^{67}$ Ibid.

${ }^{68}$ Another option considered and later apparently dropped was a trial in the fractionization of doses. See ibid. and Draft Memorandum, n.d., NA, FD 7/327.
} 


\section{Clinical Trials and Medical Research in Britain}

very poor results in this highly malignant form of carcinoma, confirming the findings in other series. $^{69}$

The working party suggested that radiotherapy might be the slightly better choice, as post-operative complications would be avoided. Follow-up for the thirteen survivors continued as planned. After five years, only one surgery patient and three in the radiotherapy group were alive. After ten years this surgery patient had also died. In fact, while originally assigned to the surgery group, he had become too breathless to withstand an operation and received palliative radiotherapy instead (he was not the only member of this group who turned out to be inoperable when surgery was scheduled). The three survivors in the radiotherapy group were still alive after ten years. ${ }^{70} \mathrm{~A}$ handwritten note in the administrative file dealing with the study states: "It seems to me that there is nothing at all controversial about this report, which is a straightforward account of a difficult but well organized clinical trial, the outcome of which has been as depressing as it was predictable."71 More depressingly, a letter debate in the Lancet following the publication of the results indicates that thoracic surgeons were not convinced that the trial had conclusively shown that radiotherapy was superior in this form of lung cancer. ${ }^{72}$ The Working Party had demonstrated that they could organize a trial in difficult circumstances, but had failed to turn this organizational triumph into any particularly useful knowledge.

The second trial initiated by the Working Party was more promising, as the question addressed was not as fundamental as the decision between surgery, a well established form of therapy, and radiotherapy, which in this form of cancer had so far not yielded particularly good results. This second trial, which started in 1964, was a study of chemotherapy as an adjuvant to surgery. Again, this was organized by the MRC Tuberculosis Research Unit. ${ }^{73}$ The preparation of the chemotherapy trial, it seems, was much smoother than in the first trial. There were no extensive debates within the Working Party and no big meetings with consultants were scheduled. One explanation for this lack of controversy may be that chemotherapy was tested only as a secondary therapy, an adjunct to surgery, to prevent the growth of secondary tumours. Moreover, radiotherapy was well established in Britain, while chemotherapy was perceived as something new-an approach that promised new channels for intervention. ${ }^{74}$ In this trial patients

${ }^{69}$ J G Scadding, J R Bignall, L G Blair, W P Cleland, et al., 'Comparative trial of surgery and radiotherapy for the primary treatment of smallcelled or oat-celled carcinoma of the bronchus: first report to the Medical Research Council by the Working-Party on the Evaluation of Different Methods of Therapy in Carcinoma of the Bronchus', Lancet, 1966, ii: 979-86, on p. 984.

${ }^{70}$ A B Miller, Wallace Fox, and Ruth Tall, 'Fiveyear follow-up of the Medical Research Council Comparative Trial of Surgery and Radiotherapy for the Primary Treatment of Small-Celled or Oat-Celled Carcinoma of the Bronchus. A report to the Medical Research Council Working Party on the Evaluation of Different Methods of Therapy in Carcinoma of the Bronchus', Lancet, 1969, ii: 501-5; Wallace Fox and
J G Scadding, 'Medical Research Council comparative trial of surgery and radiotherapy for primary treatment of small-celled or oat-celled carcinoma of bronchus: ten-year follow-up', Lancet, 1973, ii: 63-5.

${ }^{71}$ Note by J R H [Herrald], 22 August 1966, NA, FD $7 / 1151$.

${ }^{72}$ See, for example, R Abbey Smith, 'Treatment of bronchial carcinoma', Lancet, 1966, ii: 1134-5, and J R Belcher, 'Treatment of bronchial carcinoma', Lancet, 1966, ii: $1190-1$.

${ }^{73}$ NA, FD 7/327; FD 23/1163.

${ }^{74}$ For critical remarks on studies undertaken with chemotherapy in lung cancer from France, the US and Denmark, see L Israel, 'Chemotherapy in inoperable bronchial carcinoma', Lancet, 1971, 


\section{Helen Valier and Carsten Timmermann}

were randomly assigned, in a double-blind set-up, to groups that were prescribed either one of two chemotherapeutic agents, busulphan or cyclophosphamide, or a placebo. ${ }^{75}$ Recruitment and organization went very smoothly, and there were few complications. While the Working Group had now shown that it was able to organize a clinical trial in lung cancer that conformed to the new standards of a co-operative, double-blind, randomized controlled trial, the results did not fulfil their expectations: "The therapeutic results at two years are disappointing, for there is no evidence that either of the two cytotoxic drugs in the dosage used improved survival". ${ }^{76}$ After five years, 27 per cent of the patients who received cyclophosphamide were still alive, 28 per cent of those on busulphan, and 34 per cent in the placebo group. As with the first trial, these were disappointing results, and this disappointment contributed to a negative atmosphere surrounding the disease. Lung cancer was turning into a "Cinderella cancer". In the absence of hope or cures from biomedicine, its increasing incidence was often blamed on the patients themselves, the majority of whom were and are smokers or ex-smokers. ${ }^{77}$

\section{Conclusion}

The case of cancer research shows that while it was tempting to use controlled clinical trials as part of a programme of reorganization and standardization, trial organizers faced many problems in implementing their ambitious schemes and recruiting collaborators. In most cases, the results were less clear than for streptomycin and tuberculosis, and even there, as we have seen, the reality was more ambiguous than commentators today generally assume. The main success story of post-war clinical cancer research, as is well known, has not been in the treatment of solid cancers such as those of the lung, but in leukaemias and lymphomas, especially in children. ${ }^{78}$ We might want to suggest here, though, that the notion of childhood leukaemia as a curable disease emerged in spite of the results of early treatment trials which, on the surface, did not seem to give reason for significantly greater hopes than those for solid cancers. Only in the 1970s did the notion of temporary remission give way to that of cure. ${ }^{79}$ To understand these different histories, it is important to look both at the results of trials and at the institutional and cognitive contexts, the involvement of medical disciplines and the status of allied sciences, the charities and agencies that promoted research into particular forms of malignant disease, and, not least, the role of public campaigns and public images. In this context it cannot be ignored that with increasing acceptance of the link between lung cancer and cigarette smoking since the late 1950s, middle-aged smokers

i: 971-2; Franco M Muggia, Heine H Hansen, and Per Dombernowsky, 'Treatment of small-cell carcinoma of bronchus', Lancet, 1975, 1: 692.

${ }^{75}$ MRC Working Party, 'Study of cytotoxic chemotherapy as an adjuvant to surgery in carcinoma of the bronchus', Br. med. J., 1971, 2: 421-8; H Stott, R J Stephens, W Fox, and D C Roy, '5-year follow-up of cytotoxic chemotherapy as an adjuvant to surgery in carcinoma of the bronchus', Br. J. Cancer, 1976, 34: $167-73$.

\footnotetext{
${ }^{76}$ MRC Working Party, op. cit., note 75 above, p. 427.

${ }^{77}$ Ray Donnelly, Cinderella cancer: a personal history of the Roy Castle Lung Cancer Foundation, Liverpool, Bluecoat Press, 2006.

${ }^{78}$ For a celebration of this success, see James Le Fanu, The rise and fall of modern medicine, London, Little, Brown, 1999, pp. 138-56.

${ }^{79}$ G M Krueger, "“A cure is near": children, families, and cancer in America, 1945-1980', PhD dissertation, Yale University, 2003.
} 


\section{Clinical Trials and Medical Research in Britain}

have been viewed by many as less deserving of great curative efforts than young children. ${ }^{80}$ We have aimed to demonstrate with this paper that the cognitive, ethical, administrative and cultural aspects of post-war clinical research are nearly impossible to separate. One central reason for this was the existence of established institutions and practices, some already dedicated to cancer and others not, which shaped the local culture of clinical cancer research in the UK.

One of the new technologies that changed the face of clinical research was the clinical trial. The meaning of clinical trials has changed significantly since the 1950 s, when the MRC found it practicable to organize its anti-tuberculosis chemotherapy trials in Madras in order to try to circumvent entrenched British practice. ${ }^{81}$ Arguably this is a consequence of repeated reports on hopes associated with new experimental treatments since the 1960s (especially for childhood cancers) and the rigorous promotion of the randomized controlled trial as the gold standard of modern clinical research. No longer are participants in clinical trials viewed as "human guinea pigs" who above all need protection. ${ }^{82}$ The number of clinical trials has become a marker for the status of a malignant disease, designating it as potentially curable, and participation in a clinical trial has turned into a symbol of hope for patients. Lung cancer patients in the 1970s and 1980s were significantly under-represented in clinical trials. More recently, this has begun to change. Expressions of this change can be found in publications that aim to re-frame lung cancer as a potentially treatable disease rather than one that can only be prevented. ${ }^{83}$ In Britain, also, in the last few years, the Roy Castle Foundation has funded a number of studies on lung cancer. ${ }^{84}$

The early lung cancer trials we examined in this paper were not very successful in that they did not create the hopes for cure and survival that are so important for the public image of biomedicine. But how successful, more generally, were MRC attempts to turn British cancer medicine into biomedicine? It is difficult to judge the role of the Council separately from more general trends in medical research. The international model in cancer medicine increasingly became American, especially following Richard Nixon's declaration of a "War on Cancer" in 1971. However, it is clear that in Britain the MRC assumed an early central role in overseeing, organizing and funding clinical trials, especially randomized controlled trials, to create a distinctively British model embedded in a socialized healthcare system. Today, the Council's Oxford Clinical Trials Unit (CTU) is almost wholly dedicated to this technology, and much of its work deals with cancer. The unit names the Tuberculosis Research Unit (later Tuberculosis and Chest Diseases Unit) as one of its precursors. ${ }^{85}$ Its reputation rests partly on the

${ }^{80}$ Timmermann, op. cit., note 58 above.

${ }^{81}$ Valier, op. cit., note 38 above.

82 One of the main promoters of the German national centre for cancer research in Heidelberg, Karl Heinrich Bauer, for example, in 1958 argued against the term "cancer research" in the name of the new centre as this would give potential patients the idea that they might be experimented upon. See Gustav Wagner and Andrea Mauerberger, Krebsforschung in Deutschland: Vorgeschichte und
Geschichte des Deutschen Krebsforschungszentrums, Berlin, Springer, 1989, p. 74.

${ }^{83}$ See, for example, Claudia I Henschke and Peggy McCarthy, Lung cancer: myths, facts, choices, New York, Norton, 2002.

${ }^{84}$ Donnelly, op. cit., note 77 above. See also http://www.roycastle.org/ research/index.htm, accessed on 18 April 2008.

${ }^{85}$ 'CTU History', http://www.ctu.mrc.ac.uk/ History.asp, accessed on 18 April 2008. 


\section{Helen Valier and Carsten Timmermann}

involvement of its senior scientific staff in the follow-up studies on smoking and health, ${ }^{86}$ and on the work of the Cochrane Collaboration, which also had MRC roots. Thus despite the wide range of agencies that now conduct and co-ordinate clinical research in the UK, the initial central role of the MRC in this segment of clinical research has left a legacy. The British biomedical scene was and is diverse in its funding, activities, and leaders, but the post-war MRC ensured that almost all these entities would have to come into contact through a vast proliferation of standing committees, working parties and similar bodies from the 1950s onwards. For better or worse, this unification of multiple factions was a highly significant feature of post-war British biomedicine.

\footnotetext{
${ }^{86}$ Sir Richard Doll, for example, was one of the speakers at an event held in the premises of the Royal College of Physicians in 2004 to celebrate sixty years of MRC clinical research, where, with Richard Peto, he presented the results of fifty years follow-up
}

in the 'Doctors Study': Richard Doll and A Bradford Hill, 'The mortality of doctors in relation to their smoking habits: a preliminary report', $\mathrm{Br}$. med. J., 1954, i: $1451-5$. 